\title{
On Advantages of The Law of Primitive Man
}

\author{
Yulian Dind \\ Library of Hubei Provence, No.22, Gongzheng Road, Wuchang District, \\ Wuhan City, Hubei Province, China, 43000 \\ 184318400@qq.com
}

Keywords: Richness of Data, Systemic Discussion, Difference, Exploration, Deep Insight

\begin{abstract}
The question of whether there are laws in the primitive society has always attracted the attention of scholars of different subjects. Jurists are particularly concerns about this issue because it involves a series of jurisprudential major issues such as the origin, essence and role of law. Until today, scholars still do not have a unified understanding of it. But the book The Law of Primitive Man, written by E. Adamson Hoebel, the famous American legal anthropologist, gives his answer affirmatively. Many advantages such as the richness of the data, the systemic discussion of basic method of legal anthropology research, the difference between the original law and the modern law, the exploration of the regular pattern of law development and deep insights of the functions of the law can be seen in this book. It is undoubtedly such a valuable book that it is worth reading. But because of its many of the arguments in the book inevitably having its own prejudices and limitations, the readers should pay attention to them while reading.
\end{abstract}

\section{Introduction}

For more than one hundred years, a very charming question, whether the primitive society having law, has always attracted the researchers in different subjects like History, Anthropology, Ethnology, Sociology and Law. Certainly, the answer to this question is of great significance to the above subjects. To the law, it involves a series of jurisprudential major issues such as the origin, essence and role of law. ${ }^{[1]}$ In previous years, the debate in the Chinese jurists centering on the nature and basic attributes of the law also involves this question which until now, people's understanding of it is not united.

The Law of Primitive Man, written by E. Adamson Hoebel, the famous American legal anthropologist, and published by the Law Press in 2012, is one of the answers to the question. Obviously, the author gave his answer affirmatively in this book. From its first publishing in 1954 and highly praised by many scholars, the book arouses people's attention with its detailed materials and insights because of its solving many problems in law and other subjects effectively. Its sociological significance is extensive, and its technical adaptability is not limited to the original legal system, but also applies to general social relations. ${ }^{[2]}$

The procedure explored in this book is, first of all, to establish concepts and methods for studying primitive social laws. Second, the potential legal axioms in the original social culture are transformed into legal forms and regulations and analyzed accordingly. ${ }^{[3]}$ Under the complete background of the primitive society, the analysis from the simplest to the most complex original culture proves its role. The author does not intend to prove the legal system of all primitive societies, because this book does not want to provide an encyclopedic discourse on the original law. Instead of detailing the various forms of law, the author focuses on the analysis of the functions of the law. So, many advantages such as the richness of the data, the systemic discussion of basic method of legal anthropology research, the difference between the original law and the modern law, the exploration of the regular pattern of law development and deep insights of the functions of the law can be seen in this book. 


\section{Richness of Data}

With the richness of the data, the author extensively introduces the situation of some tribes retaining their original traces for centuries have been found in many parts of the world. In particular, he introduces in detail the relevant information of the five peoples according to the degree of development. Although many scholars have studied these peoples, their studies are relatively shallow and have been limited to one or two peoples. Integrating various materials and deeply discussing political and legal issues, The Law of Primitive Man exceeds previous monographs whether in terms of breadth or in depth and presents almost all the latest achievements in the study of contemporary legal anthropology. So undoubtedly, the book can provide rich materials and profound enlightenment for the origin of our research method.

\section{Systemic Discussion of Basic Method of Legal Anthropology Research}

Systematically, the author discusses the basic research method of legal anthropology from two aspects. First, he criticizes the research methods of natural jurisprudence and analytical jurisprudence and clearly delineated the nature of legal anthropology. He points out that the study of law by anthropology is entirely behavioral and empirical. ${ }^{[4]}$ Then he summarizes the three research methods of existing legal anthropology, namely the concept method, description method and case method. The so-called concept method refers to the method of collecting data to verify the original hypothesis by using the concept rules as a starting point and a frame. The users often prepare questionnaires in advance and ask the respondents to fill in it. The items listed and the words used in the questionnaires are all standard legal terms in modern society. Contrary to the idea method, the users of the description method do not have questionnaires, but rather rely on long-term continuous observation of notes to conduct research. ${ }^{[5]}$ They only pay attention to the observation and description of facts and special issues, but ignore the general principles and do not attach importance to collecting cases. The case method combines the advantages of the above two methods to make up for the insufficiency of the two. It mainly analyzes the settlement of disputes arising from cases, and looks for the legal principles and procedures of the society.

In this book, Hoebel believes that only case methods can lead to true jurisprudence. He points out that the reason why the research of law has to seize the case for analysis is because the law matures in the troubles and anticipated difficulties. The existence of the law is to guide people's actions, so that the conflict of people's rights and interests does not develop into a serious collision. Once people's rights and interests are in conflict, it plays a role in eliminating social chaos. In fact, true legal norms can only be tested in major disputes of litigation, otherwise it is difficult to determine which of the presumed rules actually dominate. A law which is always respected is full of customs. Otherwise, people will not be able to tell which are the assumed rules and which are the real legal ones. ${ }^{[6]}$

After discussing the significance of the case method, Hoebel discusses in detail the specific issues that should be taken into account when this method used such as to respect the lifestyle of the investigated group, carefully select one or more guarantors from the survey group. In addition, the investigators must grasp the language of the surveyee, understand the customs and habits, and carefully select the survey objects. ${ }^{[7]}$

\section{Difference between the Original Law and the Modern Law}

Clearly realizing that the law of the primitive society he studies having a principled difference from the modern law, Hoebel divides the law into three kinds: primitive law, ancient law, and modern law and resolutely opposes blindly and arbitrarily imposing modern legal language on the original data during the study, or using modern understanding of the law to measure the original law. Otherwise, it can be concluded that the original society only used to have no legal conclusions, or distorted the truth of the original society. However, he also points out that it cannot be concluded that the original law and the modern law have no connection and commonality. Through analysis, he believes that all laws 
have three characteristics or constituent elements: special power, bureaucratic power and regularity, although they have different manifestations in different laws. The so-called special power is the power of law. The power of bureaucrats is the power of the law enforcement agencies, the judges, or the courts', they are the defenders of the law. The regularity of law is the scientific nature of legal content.

Based on the analysis of these characteristics of the law, Hoebel gives the following definition to the law: such a social norm is a law, that is, if it is ignored or violated, it will be privileged to be a privileged person or group that has social recognition and can perform such acts in order to use physical power to threaten or actually use it. ${ }^{[8]}$ According to this definition, the existence of the law does not necessarily presuppose the existence of the state, as long as there is some kind of agency that enforces it. Started from this definition, he comes to the conclusion that the original society exists legal.

\section{Exploration of the Regular Pattern of Law Development}

Hoebel, the author of the book, explores the regular pattern of law development of human society and outlines a rough sketch of its development. First of all, he points out that the law is evolutionary, although its development path is not straightforward. Having its own particularity in the process of its development and being not go through the same stages and roads, each national or ethnic law still has the same rules to follow. Second, he believes that as a tool of social control, the law increases with the complexity of interpersonal relationships and the conflicts between members. It arises and develops because of the increasing need of society for controlling tools. He said that the more civilized mankind is, the greater the need for law, and the more human creates laws. Law is a product of social needs. ${ }^{[9]}$ And then, he discusses the general process of the emergence and development of human society law. In accordance with the way people obtain their dominant food, he divides human history into several stages of development, such as fishing and hunting culture, agricultural culture, and mechanical culture. And he also discusses the legal systems in each stage.

After discussing the historical laws of legal development, Hoebel also looks into the future of it. He believes that the laws of various countries in the world are moving in the direction of integration. Today's international law is only a world-class international one, because the threat of force and force still plays an important role in international action, which is the same as it was in primitive society. To survive and develop themselves, humans must change this situation. The birth of the United Nations and the series of laws made are the symbol of human's new steps on this road. It is now necessary for us to take the second step, the more important one. It is an in-depth analysis of the major legal systems of the contemporary world in order to find the fundamental principles that are hidden behind national laws and gradually create a unified world law. ${ }^{[10]}$

\section{Deep Insights of the Functions of the Law}

Hoebel believes that the law performs the basic function of maintaining the order of all societies except the simplest one. He concretizes the functions of the law into four types and separately discusses them. Firstly, it clarifies the relationship between individuals and maintains the coordination and unity of society. Secondly, it stipulates the Authority and methods to use power. Thirdly, it handles difficult cases and cleans up all social scum. Lastly, it redefines the relationship between the group and the individual to meet the need to maintain order when the living conditions change.

On the fourth function, Hoebel believes that the society is developmental and changeable, therefore, the law must not only maintain the existing order, but also create a new one. In fact, the law is a dynamic process in which no one solution to the problem can live forever. Therefore, the fourth function of the law is the re-regulation of relations and the reorientation of expectations. He believes that the fourth function of the law is prominently expressed in the alternation of old and new societies. At this time, new ideas and attitudes will gradually emerge and even suddenly arise. But complex 
cases, being generated in large numbers under the constant penetration of new ideas, are waiting for the law to resolve. At this time, the law represents the society to handle urgent cases with a future vision. When a new problem arises, new rules are enacted through the law so that it can be solved quickly and effectively, and the basic values of society can be realized through the law and free from being destroyed. The fourth function of the law is of great legal significance. It uses its best efforts to maintain the existing laws with sufficient flexibility to allow for the development of social organizations. It also seeks to maintain the resilience of the law so that it will not lose its binding force.

\section{Conclusion}

From the advantages above, it can be seen that The Law of Primitive Man by Hoebel is undoubtedly a very valuable book. Of course, as a scholar, many of his arguments inevitably have their own prejudices and limitations. For example, he does not explore the origin and development law of legal from the perspective of basic social contradictions. In his understanding of the law, he overemphasizes the role of power and confuses the boundaries between the state and other powers. He calls all social norms backed by strong forces as laws and gets a conclusion that law exists in the primitive society. The readers should pay attention to these fallacies while reading.

\section{References}

[1] Shaolin CHEN \& Wei GU, On right of criminal action, Beijing: China Legal Publishing House Press, 2008, pp. 51.

[2] Adam, Leonhard, Criminal Law and Procedure in Nepal, Far East Quarterly, vol.9, pp. 146-168, 1950.

[3] Jackson,H. M. G., Some Reflections on the Relation of Law to Social Anthropology, South African Journal of Science, vol.45, pp. 512-515, 1998.

[4] Lewin, Julius, The Theory Legal Science, North Carlina Law Review, vol.47, pp. 29-31, 1996.

[5] Stone, Julius. The Province and Fountion of Law: Law as Logic, Justice and Social Control: A Study in Jurisprudence, Cambridge, pp. 216-217, 1997

[6] [7][8][9][10] E. Adamson Hoebel, The Law of Primitive Man, Law Publishing House Press, 2012, pp. 2. 23. 45.204.287. 